This is the final peer-reviewed accepted manuscript of:

Francesco Della Monica, Sai V. C. Vummaleti, Antonio Buonerba, Assunta De Nisi, Magda Monari, Stefano Milione, Alfonso Grassi, Luigi Cavallo, Carmine Capacchione, Coupling of Carbon Dioxide with Epoxides Efficiently Catalyzedby Thioether-Triphenolate Bimetallic Iron(III) Complexes: Catalyst Structure-Reactivity Relationship and Mechanistic DFT Study, Advanced Synthesis \& Catalysis, 2016, 358(29), pp 3231-3243

The final published version is available online at: https://doi.org/10.1002/adsc.201600621

Rights / License:

The terms and conditions for the reuse of this version of the manuscript are specified in the publishing policy. For all terms of use and more information see the publisher's website.

This item was downloaded from IRIS Università di Bologna (https://cris.unibo.it/)

When citing, please refer to the published version. 


\title{
Coupling of Carbon Dioxide with Epoxides Efficiently Catalyzed by Thioether-Triphenolate Bimetallic Iron(III) Complexes: Catalyst Structure-Reactivity Relationship and Mechanistic DFT Study
}

\author{
Francesco Della Monica, ${ }^{a}$ Sai V. C. Vummaleti, ${ }^{\mathrm{b}}$ Antonio Buonerba, ${ }^{\mathrm{a}, \mathrm{c}}$ \\ Assunta De Nisi, ${ }^{\mathrm{c}, \mathrm{d}}$ Magda Monari, ${ }^{\mathrm{c}, \mathrm{d}}$ Stefano Milione, ${ }^{\mathrm{a}, \mathrm{c}}$ Alfonso Grassi, ${ }^{\mathrm{a}, \mathrm{c}}$ \\ Luigi Cavallo, ${ }^{\mathrm{b}, *}$ and Carmine Capacchione ${ }^{\mathrm{a}, \mathrm{c}, *}$ \\ a Dipartimento di Chimica e Biologia “Adolfo Zambelli”, Università degli Studi di Salerno, via Giovanni Paolo II, 84084 \\ Fisciano (SA), Italy \\ E-mail: ccapacchione@unisa.it \\ b KAUST Catalysis Center, King Abdullah University of Science and Technology, Thuwal 23955-6900, Saudi Arabia \\ E-mail: luigi.cavallo@kaust.edu.sa \\ c Interuniversity Consortium Chemical Reactivity and Catalysis, CIRCC, via Celso Ulpiani 27, 70126 Bari, Italy \\ d Dipartimento di Chimica G. Ciamician, Alma Mater Studiorum, Università di Bologna, via Selmi 2, 40126 Bologna, Italy
}

\begin{abstract}
A series of dinuclear iron(III $)^{\mathrm{I}}$ complexes supported by thioether-triphenolate ligands have been prepared to attain highly Lewis acidic catalysts. In combination with tetrabutylammonium bromide $(\mathrm{TBAB})$ they are highly active catalysts in the synthesis of cyclic organic carbonates through the coupling of carbon dioxide to epoxides with the highest initial turnover frequencies reported to date for the conversion of propylene oxide to propylene carbonate for iron-based catalysts $\left(5200 \mathrm{~h}^{-1} ; 120^{\circ} \mathrm{C}, 2 \mathrm{MPa}\right.$, $1 \mathrm{~h})$. In particular, these complexes are shown to be highly selective catalysts for the coupling of carbon dioxide to internal oxiranes affording the corre-
\end{abstract}

sponding cyclic carbonates in good yield and with retention of the initial stereochemical configuration. A density functional theory (DFT) investigation provides a rational for the relative high activity found for these $\mathrm{Fe}(\mathrm{III})$ complexes, showing the fundamental role of the hemilabile sulfur atom in the ligand skeleton to promote reactivity. Notably, in spite of the dinuclear nature of the catalyst precursor only one metal center is involved in the catalytic cycle.

Keywords: carbon dioxide fixation; cycloaddition; density functional theory; homogeneous catalysis; iron

\section{Introduction}

Over the last two decades an increasing interest in the use of carbon dioxide as chemical feedstock has engendered intensive efforts, in both academia and industry, in the search for new synthetic pathways to useful compounds and polymers. ${ }^{[1]}$ The main problem slowing the development of a chemistry based on $\mathrm{CO}_{2}$ as $\mathrm{C}_{1}$ building block lies in the kinetic and thermodynamic stability of this molecule that renders its conversion into valuable chemicals energetically unfavorable. Similarly to other industrially relevant processes, the key to overcome the kinetic inertness of carbon dioxide is the implementation of efficient catalytic systems that allow the conversion of $\mathrm{CO}_{2}$ to useful products under milder reaction conditions. In this context, one of the most promising synthetic routes is the development of efficient catalytic systems able to promote the coupling of $\mathrm{CO}_{2}$ with oxiranes giving the corresponding cyclic organic carbonates $(\mathrm{COCs})^{[2]}$ or polycarbonates. ${ }^{[3]}$ In particular COCs have many applications, such as polar aprotic green solvents, electrolytes in lithium-ion batteries, and as chemical intermediates in the synthesis of other small molecules or polymers. As a matter of fact, a large repertoire of catalytic systems mainly based on transition metal complexes combined with a nucleophile (quaternary ammonium salts and phosphonium salts) as co-catalyst has been developed and shown to be highly active and selective for the cyclo- 
addition of $\mathrm{CO}_{2}$ to epoxides ${ }^{[2]}$ It is worth noting that the most studied and active complexes are based on metals such as chromium, cobalt, zinc, magnesium or niobium. ${ }^{[2 \mathrm{~d}]}$ These are metals that have given rise to health and environmental concerns, and have also been recently defined as endangered elements, i.e., metals that will be not available anymore at affordable prices in the near future. ${ }^{[4]}$ This situation has triggered the search for new, greener and inexpensive catalytic systems able to efficiently promote this reaction. ${ }^{[2 \mathrm{e}]}$

The two most promising approaches to achieve this goal are: (i) the development of metal-free organocatalytic systems ${ }^{[5]}$ and (ii) the use of complexes based on Earth-crust abundant metals ( $\mathrm{Fe}, \mathrm{Al}, \mathrm{Ti}, \mathrm{Ca})$. In spite of the growing number of organocatalysts, the presence of a Lewis acidic metal center that activates the opening of the oxirane ring still offers advantages in terms of high activity, low catalyst loading and even milder reaction conditions. In this field aluminum-based catalysts have been extensively investigated. ${ }^{[6]}$ In particular, the bimetallic aluminum (salen) complex developed by North ${ }^{[6,7]}$ and co-workers and the aluminum amino-tris(phenolate) complex reported by Kleij ${ }^{[8]}$ and co-workers have been shown to be highly active and versatile catalysts for the formation of cyclic carbonates. Conversely, notwithstanding the growing interest in the use of iron in catalysis, ${ }^{[9]}$ the examples of iron-based catalysts for the formation of cyclic carbonates from $\mathrm{CO}_{2}$ and epoxides are rather scarce. ${ }^{[10]}$ We have recently reported on new catalysts based on dinuclear $\mathrm{Fe}(\mathrm{III})$ complexes (complexes 13; Scheme 1), bearing dithioether-triphenolate-based ligands in combination with tetrabutylammonium bromide (TBAB), which have proved to be highly active and versatile in the synthesis of COCs. ${ }^{[1]}$ These results have shown that it is possible to obtain efficient catalysts for the cycloaddition of $\mathrm{CO}_{2}$ to epoxides based on iron complexes, and that the presence of the hemilabile $\mathrm{Fe}-\mathrm{S}$ bond in the catalyst precursor has a beneficial role in the subsequent epoxide coordination to the metal center, promoting the formation of the cyclic carbonate in the presence of the nucleophil- ic co-catalyst. Here we report the synthesis and complete characterization of three novel iron(III) complexes 4-6 bearing dithioether-triphenolate ligands and their use as catalysts for the coupling of $\mathrm{CO}_{2}$ with epoxides and compare their performances with the known iron(III) complexes 1-3 under the same reaction conditions. In combination with $\mathrm{TBAB}$ and under optimized reaction conditions, they show high activity in the coupling of various terminal epoxides with $\mathrm{CO}_{2}$. In addition, they also convert various internal epoxides affording the corresponding carbonates in good yields and with high stereoselectivity. Density functional theory calculations (DFT) reveal that in spite of the bimetallic nature of the catalyst precursor only one metal center is involved in the catalytic cycle.

\section{Results and Discussion}

\section{Synthesis and Characterization of the Iron(III) Complexes 4-6}

The Lewis acidity of the metal center, according to the widely accepted reaction mechanism, ${ }^{[2 \mathrm{~d}]}$ should play a crucial role in the determination of the catalytic activity for the cycloaddition of carbon dioxide to oxiranes. Indeed, with the aim to increase the Lewis acidity of the iron atoms, we decided to modify the pro-ligand structure by introducing an electron-withdrawing substituent, such as chlorine, on the lateral (L4) and central (L5) phenol rings, in order to evaluate the impact on the catalytic activity in the formation of the cyclic carbonates. The methyl-substituted pro-ligand (L6) was also synthesized to have an alkylsubstituted complex (6) with a steric hindrance comparable with that of the chlorine substituted one (4). The pro-ligands $\mathbf{L} \mathbf{4}-\mathbf{L 6}$, were synthesized by a modification of the procedure previously reported (Scheme 1). ${ }^{[11]}$ All the new pro-ligands were fully characterized by nuclear magnetic resonance $\left({ }^{1} \mathrm{H},{ }^{13} \mathrm{C}\right.$ and ${ }^{1} \mathrm{H}^{13} \mathrm{C}$ HSQC NMR), mass spectrometry (ESIMS), elemental analysis (EA) and infrared spectros-

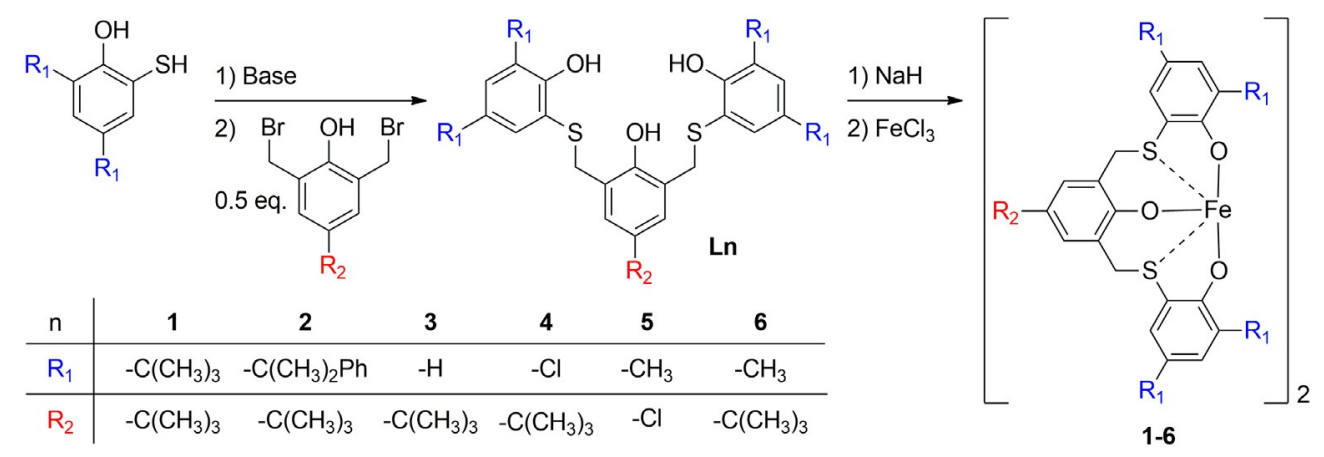

Scheme 1. Synthesis of the proligands L1-L6 and the corresponding iron(III) complexes 1--6. 
copy (FT-IR) (see the Supporting Information). Complexes 4-6, were obtained by reaction of an equimolar amount of $\mathrm{FeCl}_{3}$ with the sodium salt of the corresponding pro-ligand in THF, obtained from the reaction of the ligand precursor with 3 equivalents of sodium hydride. All the products were recovered in good yields (from 78 to $85 \%$ ), as deep-blue powders. Complexes 4-6 were characterized by elemental analysis. Furthermore, by comparison of the FT-IR spectra of complexes 4-6 with those of the corresponding ligands, disappearance of the hydroxy group vibration around $3300 \mathrm{~cm}^{-1}$ confirms the formation of the desired complexes. Moreover, the shift of the vibration bands diagnostic of the alkyl-sulfide moiety (see the Supporting Information), indicates the coordination of the sulfur atoms to the iron centers. Indeed the UV-Vis spectra of the complexes only show a strong ligand-to-metal charge transfer absorption and no $d-d$ transition as expected for two hexacoordinated HS iron(III) centers. The ESI-MS analysis was consistent with the formation of dinuclear species (Supporting Information, Figures S14-S16-S18). In addition, the values of the effective magnetic moments determined using the Evans method ${ }^{[12]}$ in toluene- $d_{8}$ at $30^{\circ} \mathrm{C}$, are comparable with the calculated value for two isolated high spin (HS) iron(III) centers $(8.37 \mu \mathrm{B}) .^{[13]}$

Notably, the magnetic moments measured in the solid state with a Johnson-Matthey balance by using the Faraday's method ${ }^{[14]}$ are in good agreement with values obtained in solution confirming that the complexes possess a dimeric structure both in the solid state and in solution (see the Supporting Information, Table S2). Finally addition of a large excess of a strong coordinating species mimicking the epoxide substrate, such as pyridine, to a toluene solution of 6 (50 equivalents with respect to 6) does not produce any change of the UV-Vis spectrum profile, underlying the stability of the dimeric structure in solution (see the Supporting Information, Figures S21-23). Single crystals of $\mathbf{6}$ were grown from a saturated acetonitrile solution; the molecular structure of the complex is shown in Figure 1. It is worth noting that each ligand is coordinated to both iron atoms with the central phenolate moiety bridging the metal centers presumably to relieve steric strain of the ligand. The molecule adopts an idealized $D_{2}$ symmetry one axis being coincident with the $\mathrm{Fe}-\mathrm{Fe}$ vector. Each iron(III) in the dimeric complex exhibits a six-coordinated $\left[\mathrm{O}_{4} \mathrm{~S}_{2}\right]$ environment generated by four phenoxo oxygens and two sulfur atoms. The $\mathrm{Fe}-\mathrm{O}$ (bridging) bond lengths in 6 are longer than the $\mathrm{Fe}-\mathrm{O}$ (non-bridging) ones. These $\mathrm{Fe}-\mathrm{O}$ distances are slightly longer, for example, than the corresponding ones found in an iron(III) thiocalix[4]arene complex. ${ }^{[15]}$ The $\mathrm{Fe}-\mathrm{S}$ interactions are rather weak and fall in the range 2.5914-2.6585(5) $\AA$ whereas the $\mathrm{Fe}-\mathrm{Fe}$ distance of $3.331 \AA$ indicates that no bonding interaction is present.
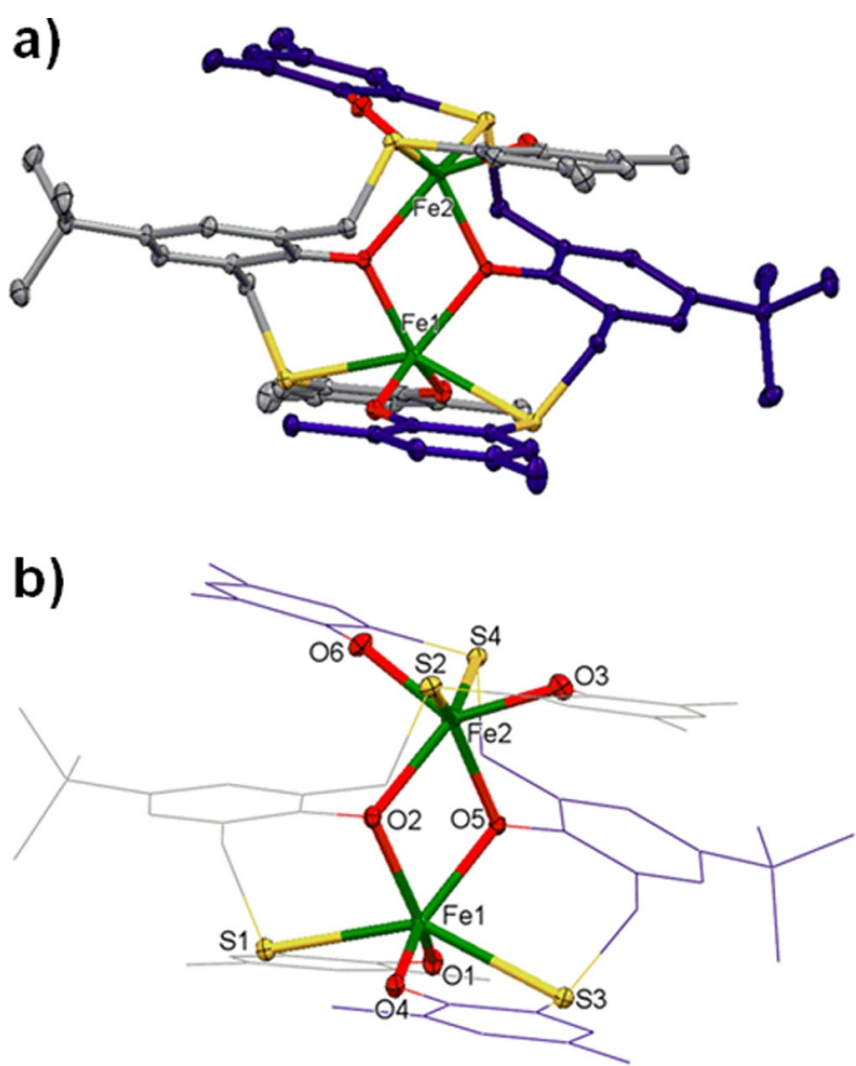

Figure 1. Molecular structure of complex 6. a) The structure is shown for the sake of clarity with the $\mathrm{C}$ atoms of one of the two ligands represented in violet color (hydrogen atoms have been omitted). Selected bond lengths $(\AA)$ : $\mathrm{Fe}(1)-\mathrm{Fe}(2)$ 3.331; $\mathrm{Fe}(1)-\mathrm{O}(1) \quad 1.8894(14) ; \quad \mathrm{Fe}(1)-\mathrm{O}(4)$ 1.9030(13); $\mathrm{Fe}(1)-\mathrm{O}(5)$ 2.0314(13); $\mathrm{Fe}(1)-\mathrm{O}(2)$ 2.0384(14); $\mathrm{Fe}(1)-\mathrm{S}(1)$ 2.6102(5); $\mathrm{Fe}(1)-\mathrm{S}(3)$ 2.6466(5); $\mathrm{Fe}(2)-\mathrm{O}(6)$ 1.8943(14); $\mathrm{Fe}(2)-\mathrm{O}(3)$ 1.8994(15); $\mathrm{Fe}(2) \mathrm{VO}(5) 2.0345(13) ; \mathrm{Fe}(2)-\mathrm{O}(2)$ 2.0514(14); $\mathrm{Fe}(2)-\mathrm{S}(2)$ 2.5914(5); $\mathrm{Fe}(2)-\mathrm{S}(4)$ 2.6585(5). b) The coordination geometry of the two iron(III) centers is highlighted.

\section{Cycloaddition of $\mathrm{CO}_{2}$ to Epoxides Promoted by Catalysts 1-6}

Aiming to optimize the reaction parameters in the cycloaddition of $\mathrm{CO}_{2}$ to $( \pm)$-propylene oxide (PO) we used the complex $\mathbf{6}$ as benchmark under solvent-free conditions. A screening of various co-catalysts, namely dimethylaminopyridine (DMAP), bis(triphenylphosphine)iminium chloride ( $\mathrm{PPNCl})$ or quaternary ammonium salts such as tetrabutylammonium chloride (TBAC), iodide (TBAI) and bromide (TBAB) in combination with 0,5 equivalent of $6(0.025 \mathrm{~mol} \%)$ was performed (see Figure $2 \mathrm{a}$ and entries S1-S5 of Table S1 in the Supporting Information).

Notably, by varying the amount of TBAB from $0.05 \mathrm{~mol} \%$ to $0.25 \mathrm{~mol} \%$ an appreciable improvement of the catalytic activity is observed (entries S5-S7, Table S1 in the Supporting Information). Increasing 


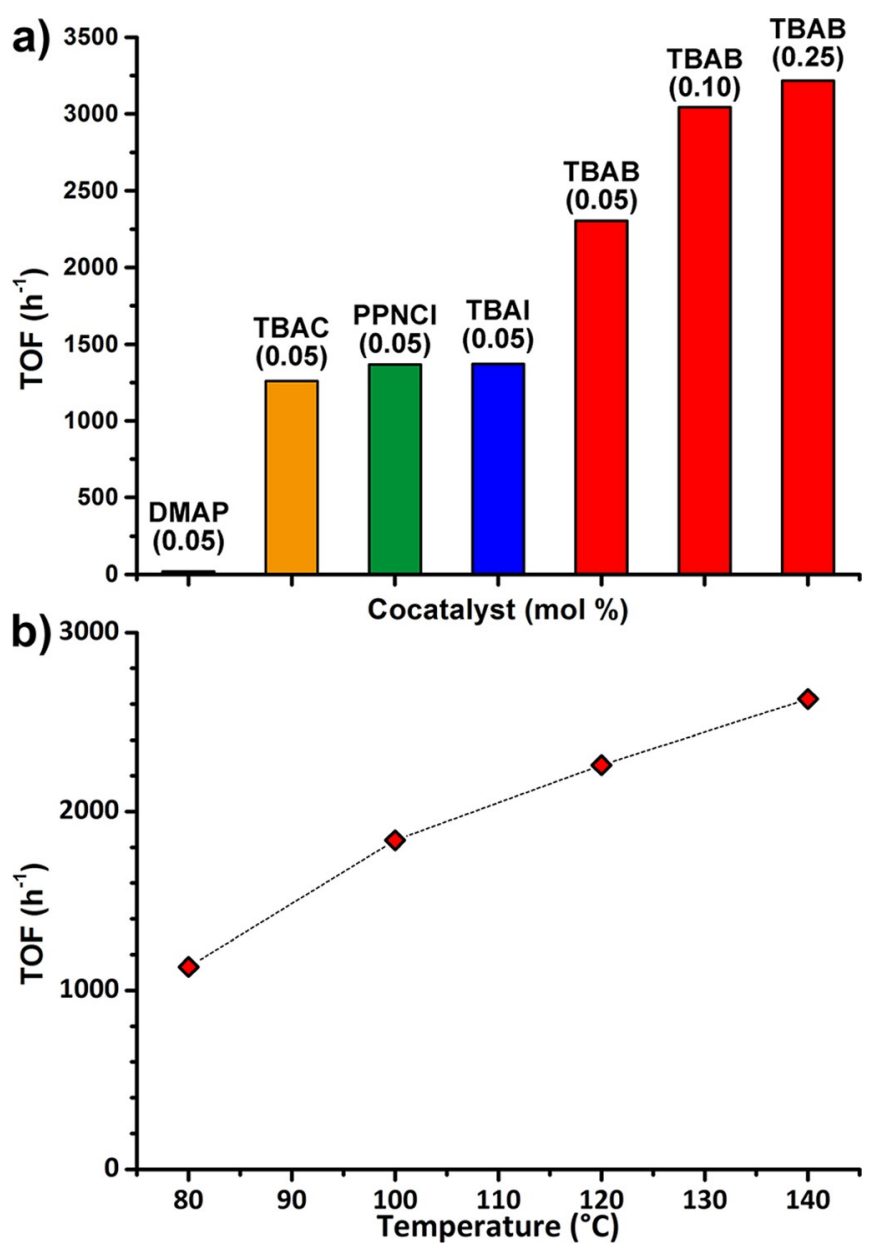

Figure 2. Effect of the co-catalyst type and loading (a) and of temperature (b) on the catalytic activity of 6 in $\mathrm{PO} / \mathrm{CO}_{2}$ coupling.

the temperature from 80 to $140^{\circ} \mathrm{C}$ results in a linear increasing of the TOF (Figure 2b; entries S5 and S8S10 of Table S1 in the Supporting Information). A control experiment using $\mathrm{TBAB}$ without the iron complex results in very low conversion $(10 \%$; entry S11, Table S1 in the Supporting Information), compared to the binary system under the same reaction conditions (80\%; entry S7, Table S1 in the Supporting Information). The effect of the $\mathrm{CO}_{2}$ pressure on the catalytic activity was also investigated (compare entries S7 and S12-S13, Table S1 in the Supporting Information); by reduction of the pressure from 2.0 to $0.5 \mathrm{MPa}$ the activity does not drop dramatically, while on increasing the pressure to $4.0 \mathrm{MPa}$ an activity enhancement from 3300 to $4000 \mathrm{~h}^{-1}$, reaching complete conversion of PO in only 1 hour, was observed.

Owing to these good results the catalyst loading was reduced from 0.025 to $0.01 \mathrm{~mol} \%$, in order to compare the catalytic activity of complexes 1-6 in the coupling of $\mathrm{CO}_{2}$ with $\mathrm{PO}$ (Table 1$)$. The best performance was achieved using complex $\mathbf{6}$, with a TOF
Table 1. $\mathrm{CO}_{2}$ /propylene oxide coupling promoted by the iron(III) complexes 1-6.

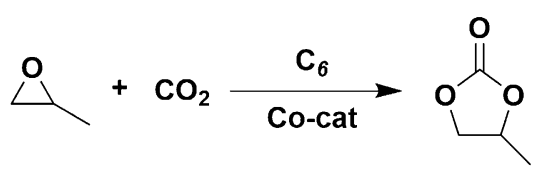

\begin{tabular}{|c|c|c|c|}
\hline Entry $^{[a]}$ & Catalyst & Conversion $^{[\mathrm{b}, \mathrm{c}]}[\mathrm{mol} \%]$ & $\mathrm{TOF}^{[\mathrm{d}]}\left[\mathrm{h}^{-1}\right]$ \\
\hline 1 & 1 & 43.0 & 4300 \\
\hline 2 & 2 & 35.5 & 3550 \\
\hline 3 & 3 & 40.4 & 4040 \\
\hline 4 & 4 & 36.3 & 3630 \\
\hline 5 & 5 & 50.0 & 4990 \\
\hline 6 & 6 & 52.0 & 5200 \\
\hline $7^{[\mathrm{e}]}$ & - & 5 & - \\
\hline \multicolumn{4}{|c|}{ 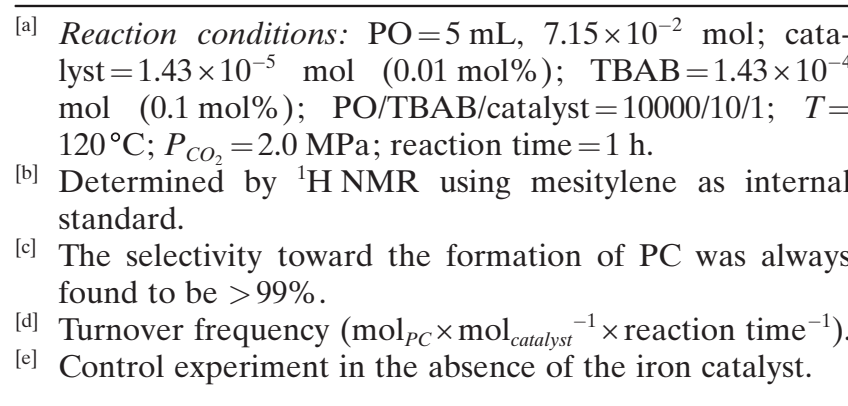 } \\
\hline
\end{tabular}

equal to $5200 \mathrm{~h}^{-1}$ at $120^{\circ} \mathrm{C}$ and $2.0 \mathrm{MPa}$ of $\mathrm{CO}_{2}$ (entry 6, Table 1). To the best of our knowledge, this is the highest TOF for an iron-based catalyst reported in literature and not far from those observed for the most active catalysts based on magnesium or aluminum. ${ }^{[2 \mathrm{~d}]}$ Complex 5 also proved to be highly active, with conversion near to that of $\mathbf{6}$ (compare entries 5 and 6 , Table 1), suggesting that the electronic effect of the substituent $R_{2}$ does not play a relevant role in the determination of the catalytic performance. On the other hand, the introduction of chlorine atoms in the $\mathrm{R}_{1}$ positions, as in complex $\mathbf{4}$, has a deleterious effect on the catalytic activity (compare entries 4 and 6 , Table 1). In addition, the appreciable lower activity displayed by complex $\mathbf{2}$, bearing the more sterically demanding cumyl groups on the phenol rings, confirms that the catalytic activity is strongly influenced by the bulkiness of the substituents on the external phenol rings.

To further evaluate the role of the steric demand around the catalytic site on the catalytic performance, the coupling of $\mathrm{CO}_{2}$ with a bulkier terminal epoxide such as the 1,2-epoxyhexane was performed (Table 2).

Both 5 and $\mathbf{6}$ exhibit again the highest activities (respectively, 3390 and $3450 \mathrm{~h}^{-1}$ ), with differences in the order of the experimental error (entries 12 and 13, Table 2). Notably, the longer alkyl chain on the epoxide ring exalts differences in the activity due to the steric hindrance of the substituents in the $\mathrm{R}_{1}$ positions, with complex 2 displaying a considerably lower 
Table 2. $\mathrm{CO}_{2}$ /hexene oxide coupling promoted by iron(III) complexes 1-6.

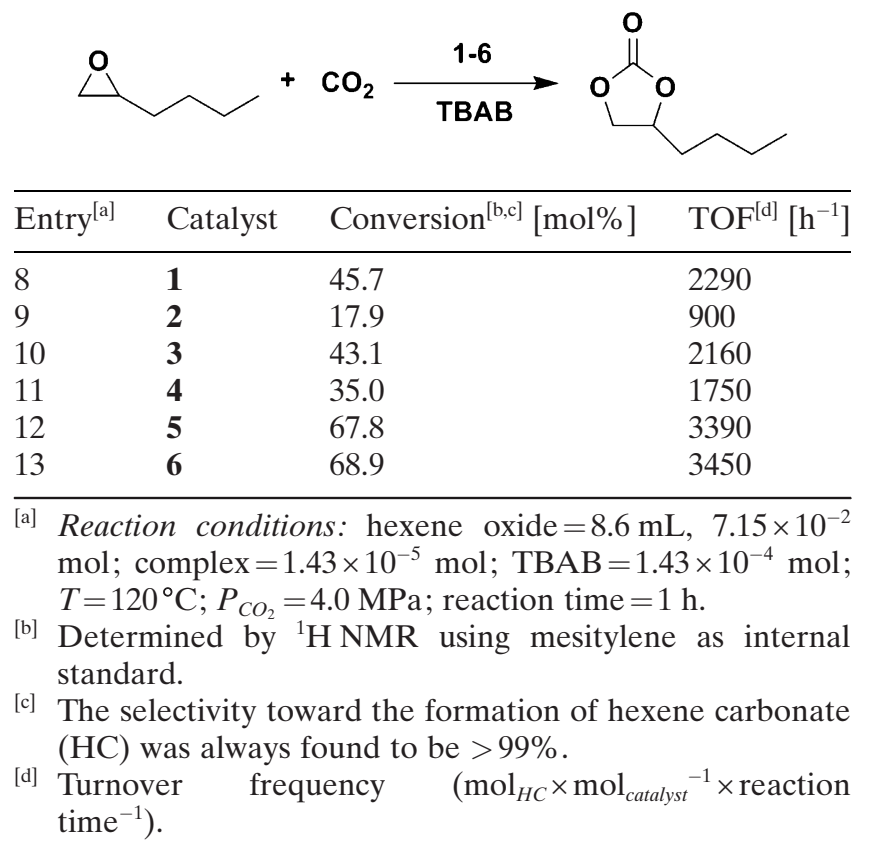

activity (entry 9, Table 2). The less sterically demanding complex $\mathbf{3}$ shows lower activity compared to $\mathbf{6}$ due to solubility issues in the reaction medium as previously reported. ${ }^{[11 \mathrm{~b}]}$ In order to investigate the applicability of the catalytic system $6 / \mathrm{TBAB}$ to a wider range of substrates, we performed the coupling reaction of carbon dioxide with a series of mono-, di-substituted and internal epoxides. The results summarized in the Table 3 clearly show that the presence of an electronwithdrawing substituent in the substrate, such as a chlorine atom in epichlorohydrin, has a positive effect with a TOF of $7000 \mathrm{~h}^{-1}$ (entry 14, Table 3).

Conversely, the presence of an electron-releasing group, such as a phenoxy or a phenyl group results in an attenuation of the reactivity (entries 15-17, Table 3$)$. Notably the more challenging substrate isobutylene oxide (1,1-dimethyloxirane) was converted in good yield to the corresponding carbonate (entry 19 of Table 3). Moreover the cis form of 1,2-dimethyloxirane was converted to the corresponding carbonate not only in good yield but also with a high degree of configuration retention (entry 20, Table 3).

Intriguingly, complex 6 in combination with TBAB retains the configuration of the starting substrate regardless of the cocatalyst/catalyst molar ratio (compare entries 20 and 21, Table 3) indicating that the attack of the bromide anion to the epoxide ring proceeds selectively via two consecutive inversions of configuration $\left(\mathrm{S}_{\mathrm{N}} 2\right)$ on the same stereocenter and that, differently to what was reported for other iron(III)-based catalysts, ${ }^{[10 f]}$ this mechanism is not dependent on the bromide concentration (see

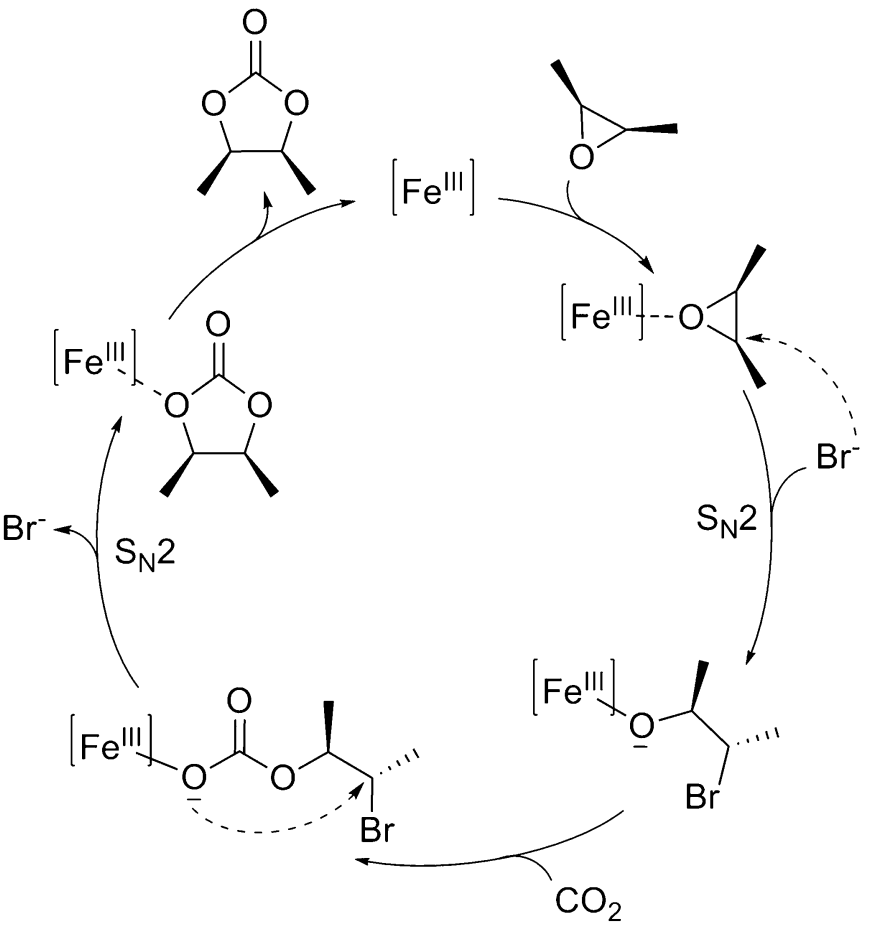

Scheme 2. Proposed mechanism for the retention of stereochemical configuration in the production of cis-4,5-dimethyl1,3-dioxolan-2-one from cis-2,3-epoxybutane and $\mathrm{CO}_{2}$ promoted by catalyst 6 in the presence of TBAB.

Scheme 2). A complete stereoretention was also observed in the case of trans-stilbene oxide (entry 22, Table 3) and the exclusive formation of cis-cyclohexene carbonate (cis-CHC) (entry 18, Table 3 ) also supports the proposed reaction mechanism. In fact, the thermodynamically disfavored formation of cis-CHC should necessarily arise from a mechanism involving a double inversion of the starting $\mathrm{CHO}$ configuration. ${ }^{[2 \mathrm{~d}]}$

\section{Theoretical Calculations}

Deeper insights into the reaction mechanism were obtained by performing DFT on the reaction mechanism for the cycloaddition of $\mathrm{CO}_{2}$ to $\mathrm{PO}$ catalyzed by complex 6 in the presence of TBAB, the complete energy profile is reported in Figure 3 (for clarity, we refer to the two $\mathrm{Fe}$ (III) centers in $\mathbf{6}$ as $\mathrm{Fe}_{1}$ and $\mathrm{Fe}_{2}$ ). Coordination of $\mathrm{PO}$ to the $\mathrm{Fe}_{1}$ center in $\mathbf{6}$ is only possible by dissociation one of the two hemilabile $\mathrm{S}$ atoms $\left[\mathrm{r}\left(\mathrm{Fe}_{1}-\right.\right.$ S) $=2.704 \AA]$.

PO coordination is calculated to be endergonic and leads to intermediate $\mathbf{6 - A}$, which lies $7.5 \mathrm{kcal} \mathrm{mol}^{-1}$ above 6. From a structural point of view, in 6-A PO coordinates to the $\mathrm{Fe}_{1}$ center $\left[\mathrm{r}\left(\mathrm{Fe}_{1}-\mathrm{O}\right)=2.412 \AA\right]$ in the coordination position previously occupied by the dissociated S atom. PO coordination results in a slight 
Table 3. $\mathrm{CO}_{2}$ /epoxide coupling promoted by iron(III) complexes 6 .

\begin{tabular}{|c|c|c|c|c|c|c|}
\hline Entry $^{[\mathrm{a}]}$ & Substrate & $\begin{array}{l}\text { Epoxide/TBAB/6 (molar } \\
\text { ratio) }\end{array}$ & Product & $\begin{array}{l}\text { Conversion }^{[\mathrm{b}, \mathrm{c}]} \\
{[\mathrm{mol} \%]}\end{array}$ & $\begin{array}{l}\text { cis:trans }{ }^{[\mathrm{d}]} \text { (molar } \\
\text { ratio) }\end{array}$ & $\begin{array}{l}\mathrm{TOF}^{[\mathrm{e}]} \\
{\left[\mathrm{h}^{-1}\right]}\end{array}$ \\
\hline 14 & & $10000 / 10 / 1$ & $\mathrm{O}_{y}$ & 70.0 & - & 7000 \\
\hline 15 & & $10000 / 10 / 1$ & & 44.5 & - & 4450 \\
\hline 16 & & $10000 / 10 / 1$ & & 21.0 & - & 2100 \\
\hline 17 & & $10000 / 10 / 1$ & & 13.0 & - & 1300 \\
\hline $18^{[\mathrm{f}]}$ & & $1000 / 10 / 1$ & & 55.0 & $>99: 1$ & 550 \\
\hline $19^{[\mathrm{f}, \mathrm{g}]}$ & & $1000 / 10 / 1$ & & 65.8 & - & 660 \\
\hline $20^{[\mathrm{f}, \mathrm{g}]}$ & & $1000 / 10 / 1$ & & 67.1 & $97: 3$ & 670 \\
\hline $21^{[\mathrm{f}, \mathrm{g}]}$ & & $1000 / 2 / 1$ & & 12.6 & $98: 2$ & 125 \\
\hline $22^{[\mathrm{g}, \mathrm{h}]}$ & & 1000/10/1 & & 7.3 & $>1: 99$ & 70 \\
\hline
\end{tabular}

[a] Reaction conditions: epoxide $=7.15 \times 10^{-2} \mathrm{~mol} ; T=120^{\circ} \mathrm{C} ; \mathrm{P}_{\mathrm{CO}_{2}}=2.0 \mathrm{MPa}$; reaction time $=1 \mathrm{~h}$.

[b] Determined by ${ }^{1} \mathrm{H}$ NMR using mesitylene as internal standard.

[c] The selectivity toward the formation of cyclic carbonate was always found $>99 \%$.

[d] Determined by ${ }^{1} \mathrm{H}$ NMR.

[e] Turnover frequency $\left(\mathrm{mol}_{\text {carbonate }} \times \mathrm{mol}_{\text {catalyst }}{ }^{-1} \times\right.$ reaction time $\left.{ }^{-1}\right)$.

[f] Epoxide $=1.0 \mathrm{~mL}$.

[g] $P_{\mathrm{CO}_{2}}=4.0 \mathrm{MPa}$.

[h] Stilbene oxide $=1.0 \mathrm{~g}, \mathrm{MEK}=2.0 \mathrm{~mL}$.

decrease in the $\mathrm{Fe}_{1}-\mathrm{Fe}_{2}$ distance in 6-A when compared to the catalyst species 6 (3.271 vs. $3.364 \AA$, respectively; see Figure 4).

To explore the eventual dissociation of one of the two $\mathrm{Fe}_{1}-\mathrm{S}$ bonds prior to $\mathrm{PO}$ coordination in the starting complex 6, we removed PO from the optimized geometry of intermediate 6-A and we re-optimized the complex. The resulting complex with $\mathrm{Fe}_{1}-\mathrm{S}$ bond being dissociated is lying only $5.8 \mathrm{kcal} \mathrm{mol}^{-1}$ above species $\mathbf{6}$, in line with the expected lability of the $\mathrm{S}$ binding. The experimental evidence that the introduction of the electron-withdrawing chlorine atoms on the lateral phenol rings (complex 4) results in a lowering of the catalytic activity supports this sce- nario. As a matter of fact, the coordinating ability of the phenoxide $\mathrm{O}$ atoms should be reduced in $\mathbf{4}$ due to the presence of the ortho $\mathrm{Cl}$ atom. This should result in increased Lewis acidity at the metal center and should reduce the lability of the sulfur atoms, rendering substitution of one sulfur moiety by PO less favorable. This scenario is supported by our calculations on complex 4, which presents slightly shorter $\mathrm{Fe}_{1}-\mathrm{S}$ distances when compared to complex 6 (2.66 $\mathrm{A} v s$. $2.70 \AA$, see Figure S1 in the Supporting Information). Consistently, dissociation of one $\mathrm{Fe}_{1}-\mathrm{S}$ bond from complex 4 requires $8.6 \mathrm{kcal} \mathrm{mol}^{-1}$ versus $5.8 \mathrm{kcal} \mathrm{mol}^{-1}$ in $\mathbf{6}$, and the PO coordinated intermediate $\mathbf{4 - A}$, is slightly less stable than 6-A (8.7 vs. $\left.7.5 \mathrm{kcal} \mathrm{mol}^{-1}\right)$. 


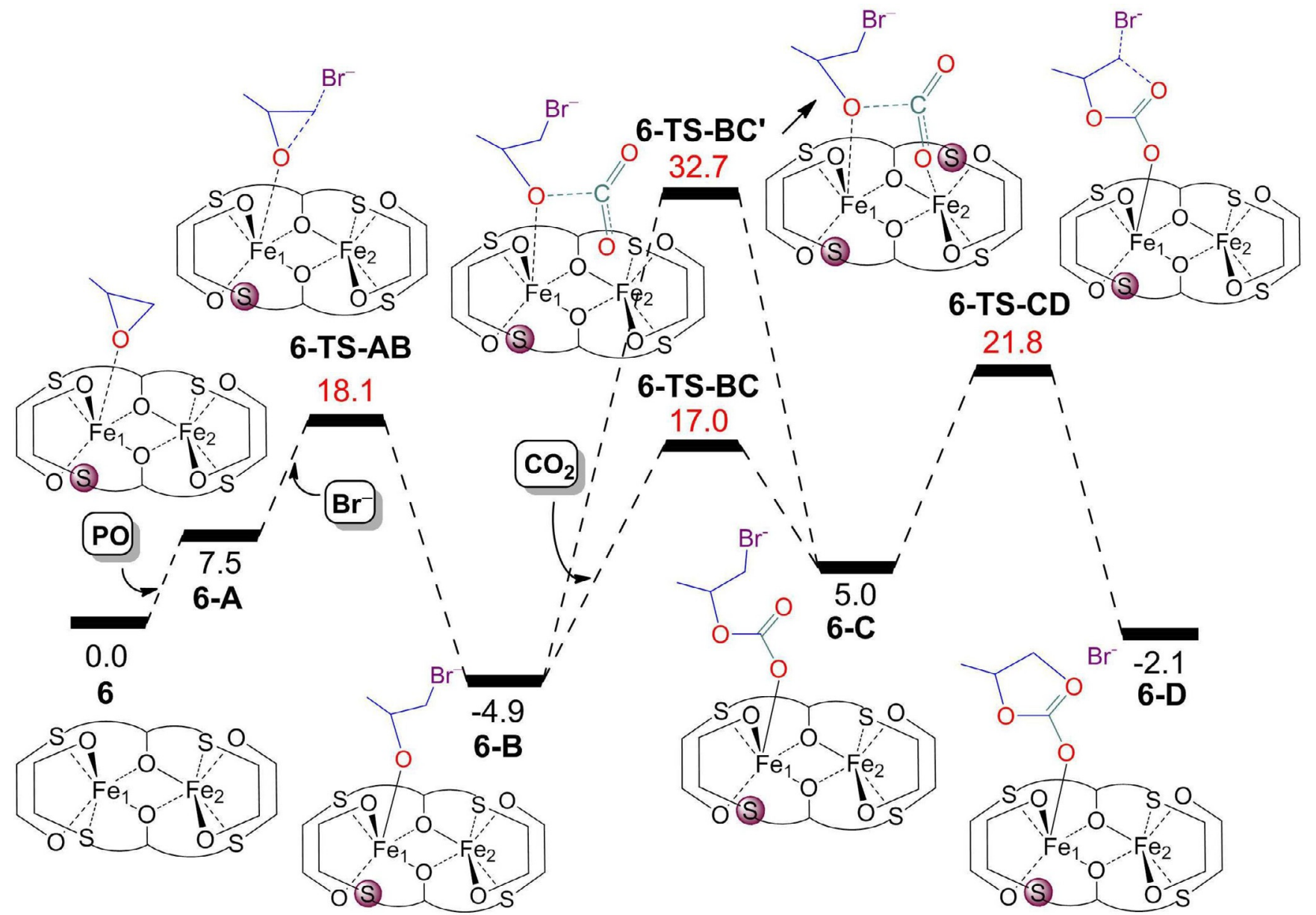

Figure 3. Computed free energy surface for the cycloaddition of propylene oxide (PO) and $\mathrm{CO}_{2}$ catalyzed by species $\mathbf{6}$ / TBAB. The free energies in solution ( $\mathrm{PO}$ as the solvent) are given in $\mathrm{kcal} \cdot \mathrm{mol}^{-1}$ relative to the starting complex $\mathbf{6}$. The energy values in red represent the energies of the transition states. indicates decoordination of a hemilabile $\mathrm{S}$ atom.

Back to the main mechanism catalyzed by $\mathbf{6}$, the next step from the PO coordinated specie 6-A corresponds to the opening of the $\mathrm{PO}$ ring by a $\mathrm{Br}$ anion, leading to the formation of the more stable intermediate 6-B, $5.5 \mathrm{kcal} \mathrm{mol}^{-1}$ below 6. This step proceeds through transition state 6-TS-AB and requires overcoming an overall barrier of $18.1 \mathrm{kcal} \mathrm{mol}^{-1}$ above $\mathbf{6}$. Then, we studied insertion of $\mathrm{CO}_{2}$ into the $\mathrm{Fe}-\mathrm{O}$ bond in the intermediate 6-B to give the hemicarbonate intermediate 6-C, which lies $10.0 \mathrm{kcal} \mathrm{mol}^{-1}$ above 6-B. This $\mathrm{CO}_{2}$ insertion step requires the overcoming of a barrier (6-TS-BC) of $21.9 \mathrm{kcalmol}^{-1}$ from the most stable intermediate 6-B. To our surprise, despite the relatively low calculated barrier we did not observe any cooperativity between the two Fe centers, since the $\mathrm{CO}_{2}$ molecule is quite a way away from the $\mathrm{Fe}_{2}$ center $\left[\mathrm{r}\left(\mathrm{Fe}_{2}-\mathrm{CO}_{2}\right)=3.772 \AA\right]$, see Figure 5a.

As a further check on the possible cooperativity between the two $\mathrm{Fe}$ centers in the $\mathrm{CO}_{2}$ insertion step, we calculated an alternative transition state for $\mathrm{CO}_{2}$ insertion, 6-TS-BC ${ }^{\prime}$, by forcing decoordination of one of the two hemilabile $\mathrm{S}$ atoms from the $\mathrm{Fe}_{2}$ center. In this case we observed a clear interaction between the $\mathrm{Fe}_{2}$ center and one of the $\mathrm{O}$ atoms of the $\mathrm{CO}_{2}$ molecule $\left[\mathrm{r}\left(\mathrm{Fe}_{2}-\mathrm{CO}_{2}\right)=2.320 \AA\right]$, see Figure 5b. However, transition state $\mathbf{6 - T S}-\mathbf{B C}^{\prime}$ is placed $15.7 \mathrm{kcal} \mathrm{mol}^{-1}$ higher in energy relative to transition state 6-TS-BC. These observations suggest that though the catalyst species 6 under investigation is bimetallic, catalysis essentially occurs at a single $\mathrm{Fe}(\mathrm{III})$ center without cooperation of the second $\mathrm{Fe}$ (III) center. This is clearly different from the case of $\mathrm{PO}$ coupling with $\mathrm{CO}_{2}$ to afford the cyclic carbonate promoted by monometallic $\mathrm{Nb}$ complexes, where cooperativity between two $\mathrm{Nb}$ centers occurs both in the homogeneous phase as well as after grafting of the $\mathrm{Nb}$ complex on silica. ${ }^{[16]}$ Next, starting from intermediate $\mathbf{6}-\mathbf{C}$, we studied the ring closing step leading to the formation of intermediate 6-D with the desired cyclic carbonate product coordinated to the Fe metal center. According to calculations, ring closing is predicted to be the rate-determining step, with a barrier of $26.7 \mathrm{kcal} \mathrm{mol}^{-1}$ (6-TSCD) relative to the most stable intermediate 6-B. This is clearly a high barrier, which is however consistent 

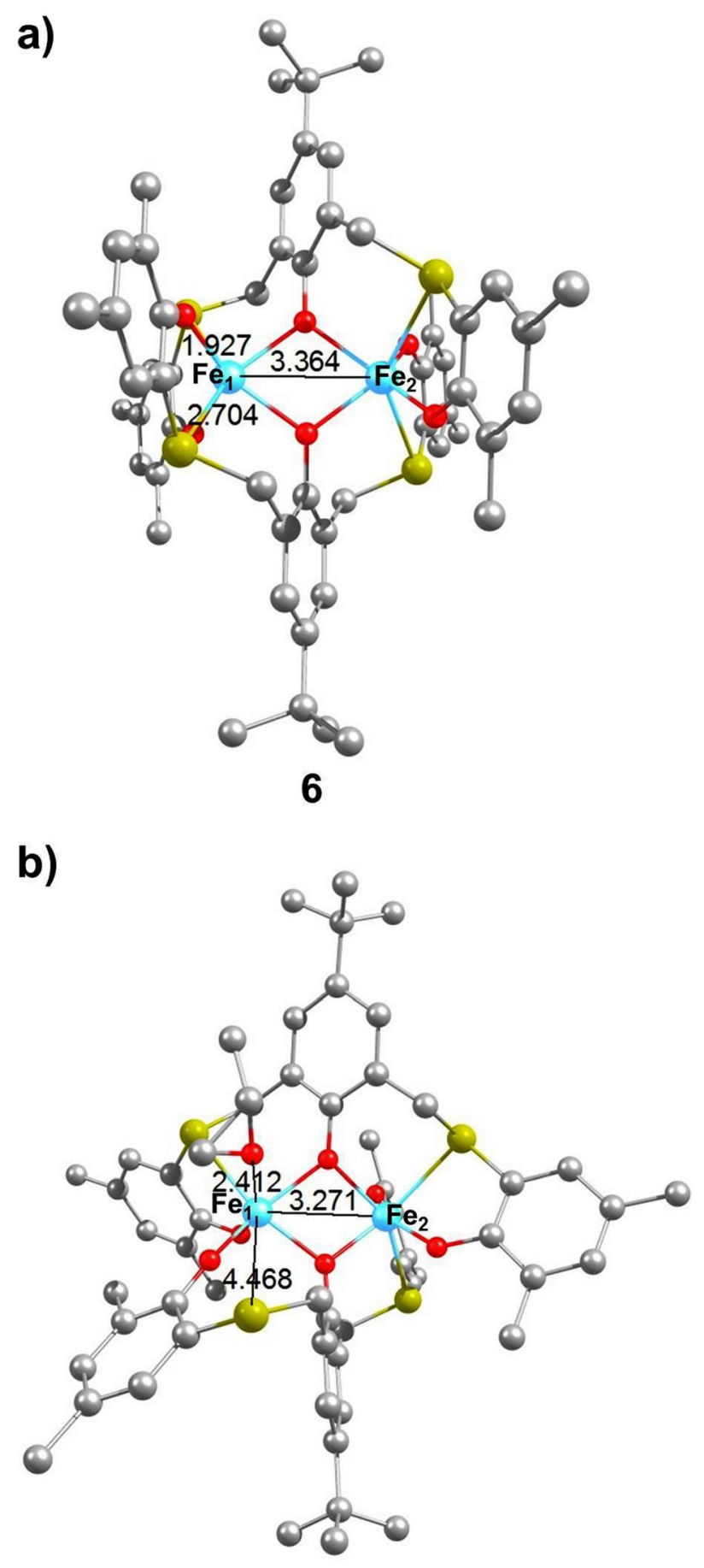

\section{6-A}

Figure 4. Geometry of the starting complex 6 (a) and of the PO coordinated intermediate 6-A (b). Hydrogen atoms omitted for clarity and the selected distances in $\AA$.

with the remarkably high temperature of $120^{\circ} \mathrm{C}$ needed experimentally to achieve a yield of at least $51 \%$ in 1 hour. Finally, intermediate 6-D would release the carbonate product and $\mathrm{a} \mathrm{Br}^{-}$anion, regenerating intermediate 6-A with recoordination of a free PO molecule, thus closing the catalytic cycle.

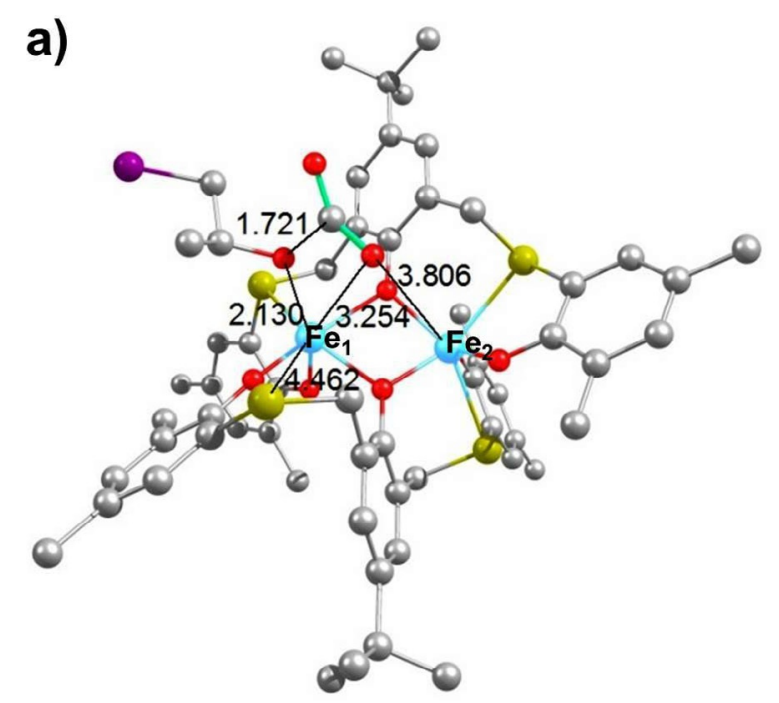

6-TS-BC

b)

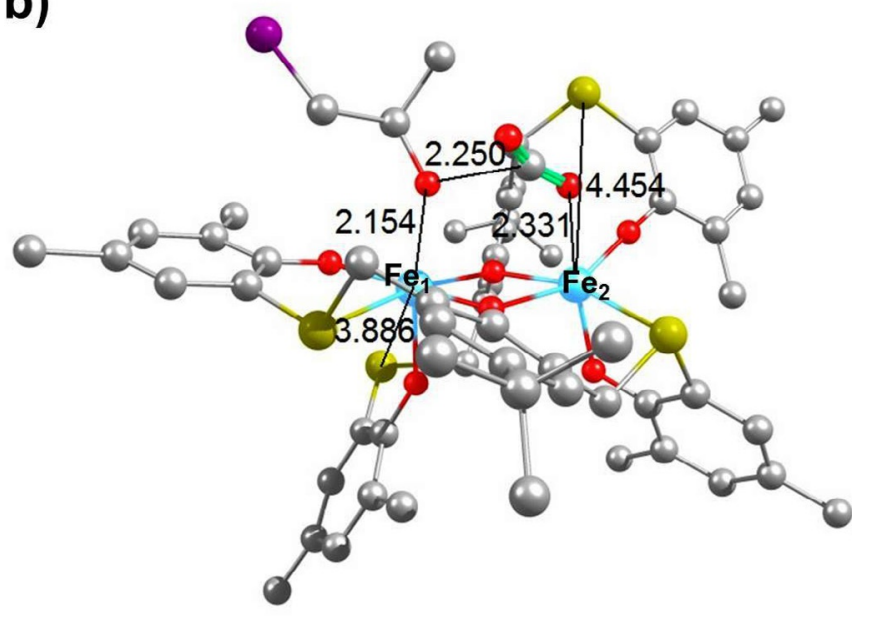

\section{6-TS-BC}

Figure 5. Geometry of transition states 6-TS-BC (a) 6-TSBC' (b), for insertion of $\mathrm{CO}_{2}$ into the $\mathrm{Fe}-\mathrm{O}$ bond. Hydrogen atoms omitted for clarity and the selected distances in $\AA$.

\section{Conclusions}

We have reported the synthesis and the complete characterization of three novel bimetallic iron(III) complexes (4-6) bearing thioether-triphenolate ligands. When activated by tetrabutylammonium bromide the title iron(III) complexes prove to be very effective in the cycloaddition of $\mathrm{CO}_{2}$ to epoxides giving the highest initial activity so far reported for an ironbased catalyst. In particular, complex $\mathbf{6}$ shows the best catalytic performance in terms of activity and selectivity for several terminal epoxides with TOF values up to $5200 \mathrm{~h}^{-1}$ for the conversion of PO to PC. Furthermore, complex 6 also promotes the conversion to the corresponding cyclic carbonates of internal epoxides 
with a high degree of stereocontrol in the ring-closing reaction, leading to the retention of configuration of the starting epoxide ( $\geq 97 \%$ ) via a mechanism involving a double inversion of the initial epoxide configuration. Finally the mechanistic studies show that in spite of the dinuclear nature of the catalyst precursor only one metal center is operative in the catalytic cycle and that coordination of the substrate and the subsequent reaction pathway can only take place by dissociation of a hemilabile $\mathrm{S}$ atom from one of the iron centers. These findings not only show that is possible to obtain highly active catalytic systems based on iron(III) for the $\mathrm{CO}_{2}$ /epoxides coupling but also highlight the fundamental role of these sulfur-containing ligands in modulating the Lewis acidity of the iron center and thus the reactivity with $\mathrm{CO}_{2}$ and oxiranes for this family of catalysts.

\section{Experimental Section}

All manipulations involving air- and/or moisture-sensitive compounds were performed under a nitrogen atmosphere using standard Schlenk technique and a MBraun glovebox. Toluene (99.5\%; Sigma-Aldrich) and THF (99\%; Sigma-Aldrich) were used as received or refluxed for $48 \mathrm{~h}$ over sodium or sodium ketyls and distilled before use for moisture- and oxygen-sensitive reactions. All other reagents were used as received (TCI or Sigma-Aldrich) or distilled under reduced pressure over calcium hydride. The ligand precursors: 2,6-[(3,5-di-tert-butyl-2-hydroxyphenyl)thio]-4tert-butylphenol (L1), 2,6-[(3,5-bis- $\alpha, \alpha^{\prime}$-dimethylbenzyl-2-hydroxyphenyl)thio]-4-tert-butylphenol (L2), 2,6-[(2-hydroxyphenyl)thio]-4-tert-butylphenol (L3) and the corresponding iron(III) complexes (1, 2, 3, Scheme 2) were synthesized according to the reported procedures. ${ }^{[11]}$ Deuterated solvents were purchased from Euriso-Top or Sigma-Aldrich and used as received. NMR spectra were collected on Bruker Avance spectrometers $\left(600,400,300\right.$ or $250 \mathrm{MHz}$ for $\left.{ }^{1} \mathrm{H}\right)$ : the chemical shifts were referenced to tetramethylsilane (TMS) as external reference using the residual protio signal of the deuterated solvents. Measurements of effective magnetic moments were performed on a Bruker Avance $600 \mathrm{MHz}$ spectrometer at $25^{\circ} \mathrm{C}$ in toluene- $d_{8}$ using a $5 \mathrm{~mm}$ Wilmad coaxial insert NMR tube. ${ }^{[12]}$ Solutions of the complex $4(2.22 \mathrm{mM}), 5(2.29 \mathrm{mM})$ and $\mathbf{6}(2.16 \mathrm{mM})$ in toluene$d_{8}$ with $1 \%(\mathrm{v} / \mathrm{v})$ of TMS were prepared under a nitrogen atmosphere. The effective magnetic moment $\left(\mu_{e f f}\right)$ was calculated from $\mu_{e f f}=8 \chi_{g} \mathrm{M}_{w} \mathrm{~T}$, where $\chi_{g}\left(\mathrm{~cm}^{3} \mathrm{~g}^{-1}\right)$ is the corrected molar susceptibility derived from $\chi_{g}=3 \Delta_{f} / 4 \pi f_{0} \mathrm{CM}_{w}+\chi_{\mathrm{o}} . \Delta_{f}$ is the shift in frequency $(\mathrm{Hz})$ of the residual protio signal of the solvent in the presence of the complex from the value of the pure solvent, $\mathrm{C}$ and $\mathrm{M}_{w}$ are, respectively, the concentration $\left(\mathrm{mol} \mathrm{cm}{ }^{-3}\right)$ and the molecular weight of the complex $\left(\mathrm{g} \mathrm{mol}^{-1}\right), f_{\mathrm{o}}$ is the operating frequency of the spectrometer $(\mathrm{Hz})$, and $\chi_{0}$ is the mass susceptibility of the pure solvent $\left(-0.6179 \times 10^{-6} \mathrm{~cm}^{3} \cdot \mathrm{g}^{-1}\right.$ for toluene- $\left.d_{8}\right) .4 \pi / 3$ is the shape factor for a cylindrical sample in a superconducting magnet. The magnetic susceptibilities of all the complexes 1-6 in the solid state were measured using a Sherwood Scientific MK
1 magnetic susceptibility balance by means of the Faraday method based on the following equation: $f_{s} / f_{\mathrm{r}}=\left(\chi_{\mathrm{s}} \cdot \mathrm{ms}\right) /$ $\left(\chi_{\mathrm{r}} \cdot \mathrm{m}_{\mathrm{r}}\right)$ where $f_{s}, \chi_{\mathrm{s}}$ and $\mathrm{ms}$ are the magnetic force, the specific susceptibility and the mass of the sample, while $f_{\mathrm{r}}, \chi_{\mathrm{r}}$ and $\mathrm{m}_{\mathrm{r}}$ are the magnetic force, the specific susceptibility and the mass of $\mathrm{CuSO}_{4} \cdot 5 \mathrm{H}_{2} \mathrm{O}$ used as reference compound with a value of $\chi_{\mathrm{r}}=6.00 \cdot 10^{-6} \mathrm{~cm}^{3} \cdot \mathrm{g}^{-1} \cdot{ }^{[14]}$ Magnetic moments were calculated using the following equation: $\mu_{\text {eff }}=2.828$. $\left(\mathrm{T} \cdot \chi_{\mathrm{m}}\right)^{1 / 2}$, where $\mu_{\text {eff }}$ is the effective magnetic moment, $\mathrm{T}$ is the absolute temperature and $\chi_{\mathrm{m}}$ is the molar susceptibility. Effective magnetic moments values for all complexes in both solution and solid state are listed in Table S2 of the Supporting Information. Elemental analysis was performed on a CHNS Thermo Scientific Flash EA 1112 equipped with a thermal conductivity detector. ESI-MS were acquired on a Quattro micro ${ }^{\mathrm{TM}}$ API triple quadrupole mass spectrometer from Waters equipped with electrospray ion source, using anhydrous acetonitrile as solvent. FT-IR measurements were carried out on a Bruker Vertex 70 spectrometer equipped with DTGS detector and a $\mathrm{Ge} / \mathrm{KBr}$ beam splitter. The samples were analyzed in chloroform solutions or in the solid state as $\mathrm{KBr}$ disks. UV-Vis spectra were collected on a Perkin-Elmer Lambda EZ 201 spectrophotometer.

\section{Synthesis of the Pro-ligand 2,6-[(3,5-Dichloro-2- hydroxyphenyl)thio]-4-tert-butylphenol (L4, Scheme 2)}

The pro-ligand $\mathbf{L} \mathbf{4}$ was synthesized using a modification of the previously reported procedure for L1. ${ }^{[11]}$ A $100-\mathrm{mL}$ twoneck round-bottom flask equipped with condenser and magnetic stirring bar was charged with $0.76 \mathrm{~g}$ of 2-mercapto-4,6dichlorophenol $(3.9 \mathrm{mmol})$ dissolved in $4 \mathrm{~mL}$ of ethanol, $1.4 \mathrm{~g}$ of $\mathrm{Cs}_{2} \mathrm{CO}_{3}(4.3 \mathrm{mmol})$ and the mixture was refluxed for $2 \mathrm{~h}$ until complete dissolution of $\mathrm{Cs}_{2} \mathrm{CO}_{3} .0 .66 \mathrm{~g}$ of 2,6-dibromomethyl-4-tert-butylphenol $(1.96 \mathrm{mmol})$ dissolved in $2 \mathrm{~mL}$ of ethanol were slowly added at $0^{\circ} \mathrm{C}$ and the mixture was refluxed overnight. The solvent was distilled off, water was added until dissolution of the residue and the aqueous phase extracted twice with $\mathrm{CH}_{2} \mathrm{Cl}_{2}$. The combined organic phases were dried with $\mathrm{MgSO}_{4}$ and, after evaporation of the solvent, the product was purified by column chromatography (eluent: $\mathrm{CH}_{2} \mathrm{Cl}_{2}$ ) and recovered as a white solid; yield: $0.94 \mathrm{~g}(85 \%) .{ }^{1} \mathrm{H} \mathrm{NMR}\left(600 \mathrm{MHz}, \mathrm{CD}_{2} \mathrm{Cl}_{2}, 25^{\circ} \mathrm{C}\right): \delta=1.12$ $(9 \mathrm{H}, \mathrm{s}), 4.04(4 \mathrm{H}, \mathrm{s}), 6.80(2 \mathrm{H}, \mathrm{s}, \mathrm{Ar}-\mathrm{H}), 7.19(2 \mathrm{H}, \mathrm{d}, \mathrm{Ar}-$ $\mathrm{H}), 7.32(2 \mathrm{H}, \mathrm{d}, \mathrm{Ar}-\mathrm{H}) ;{ }^{13} \mathrm{C} \mathrm{NMR}\left(600 \mathrm{MHz}, \mathrm{CD}_{2} \mathrm{Cl}_{2}\right.$, $\left.25^{\circ} \mathrm{C}\right): \delta=31.36,34.21,36.55,121.08,121.98,123.05,124.99$, $127.99,130.83,134.07,143.75,150.61,152.14$; elemental analysis: calcd. for $\mathrm{C}_{24} \mathrm{H}_{22} \mathrm{Cl}_{4} \mathrm{O}_{3} \mathrm{~S}_{2}$ : C 51.08, H 3.93, S 11.36; found: C 51.02, H 3.82. S 11.25; MS: $m / z=586.7\left(\mathrm{M}+\mathrm{Na}^{+}\right)$.

\section{Synthesis of the Pro-ligand 2,6-[(3,5-Dimethyl-2- hydroxyphenyl)thio]-4-chlorophenol (L5, Scheme 2)}

The pro-ligand $\mathbf{L 5}$ was synthesized using a modification of the previously reported procedure for L1. ${ }^{[1]}$ A $100-\mathrm{mL}$ twoneck round-bottom flask equipped with condenser and magnetic stirring bar was charged with $0.80 \mathrm{~g}$ of 2-mercapto-4,6dimethylphenol $(5.2 \mathrm{mmol})$ dissolved in $13 \mathrm{~mL}$ of DMF, $0.90 \mathrm{~g}$ of $\mathrm{K}_{2} \mathrm{CO}_{3}(6.5 \mathrm{mmol})$ and the resulting mixture was refluxed for $2 \mathrm{~h}$. $0.82 \mathrm{~g}$ of 2,6-dibromomethyl-4-chlorolphenol $(2.6 \mathrm{mmol})$ dissolved in $7 \mathrm{~mL}$ of DMF were slowly 
added at $0{ }^{\circ} \mathrm{C}$ and was refluxed overnight. The solvent was distilled off, water was added and the aqueous phase extracted twice with $\mathrm{CH}_{2} \mathrm{Cl}_{2}$. The combined organic phases were dried with $\mathrm{MgSO}_{4}$ and, the product was recovered after evaporation of the solvent as a white solid; yield: $0.97 \mathrm{~g}(81 \%)$. ${ }^{1} \mathrm{H} \mathrm{NMR}\left(400 \mathrm{MHz}, \mathrm{CD}_{2} \mathrm{Cl}_{2}, 25^{\circ} \mathrm{C}\right): \delta=2.17$ $(6 \mathrm{H}, \mathrm{s}), 2.23(6 \mathrm{H}, \mathrm{s}), 3.86(4 \mathrm{H}, \mathrm{s}), 6.11(1 \mathrm{H}, \mathrm{s}$ broad, $-\mathrm{OH})$, $6.54(2 \mathrm{H}, \mathrm{s}$ broad, $-\mathrm{OH}), 6.76(2 \mathrm{H}, \mathrm{s}, \mathrm{Ar}-\mathrm{H}), 6.92(2 \mathrm{H}, \mathrm{s}$, Ar-H), 6.95 (2H,s, Ar-H); ${ }^{13} \mathrm{C} \mathrm{NMR} \mathrm{(400} \mathrm{MHz,} \mathrm{CD}_{2} \mathrm{Cl}_{2}$, $\left.25^{\circ} \mathrm{C}\right): \delta=16.48,20.36,36.52,116.53,124.38,125.27,126.23$, $129.69,129.89,133.83,134.03,151.25,153.23$; elemental analysis calcd. for $\mathrm{C}_{24} \mathrm{H}_{25} \mathrm{Cl}_{2} \mathrm{O}_{3} \mathrm{~S}_{2}$ : C 62.52, $\mathrm{H}$ 5.47, S 13.91; found: C 62.49, H 5.42, S 13.87; MS: $m / z=483.6\left(\mathrm{M}+\mathrm{Na}^{+}\right)$.

\section{Synthesis of the Pro-ligand 2,6-[(3,5-Dimethyl-2- hydroxyphenyl)thio]-4-tert-butylphenol (L6, Scheme 2)}

The pro-ligand $\mathbf{L 6}$ was synthesized using the previously reported procedure for $\mathbf{L 1}^{[11]}$ A $100-\mathrm{mL}$ two-neck roundbottom flask equipped with condenser and magnetic stirring bar was charged with $3.14 \mathrm{~g}$ of 2-mercapto-4,6-dimethylphenol $(20.4 \mathrm{mmol})$ dissolved in $20 \mathrm{~mL}$ of ethanol, $0.90 \mathrm{~g}$ of $\mathrm{NaOH}(22.4 \mathrm{mmol})$ and the mixture was refluxed about 1 hour until complete dissolution of the hydroxide. $3.42 \mathrm{~g}$ of 2,6-dibromomethyl-4-tert-butylphenol (10.2 mmol) dissolved in $15 \mathrm{~mL}$ of ethanol were slowly added at $0^{\circ} \mathrm{C}$ and the mixture heated to the reflux of the solvent that was kept overnight. The solvent was distilled off, water was added until dissolution of $\mathrm{NaBr}$ by-product and the aqueous phase extracted twice with $\mathrm{CH}_{2} \mathrm{Cl}_{2}$. The combined organic phases were dried with $\mathrm{MgSO}_{4}$, after evaporation of the solvent the product was purified by column chromatography (petroleum ether : ethyl acetate $=95: 5)$ and recovered as a white solid; yield: $2.82 \mathrm{~g}$ (57.3\%). ${ }^{1} \mathrm{H} \mathrm{NMR}\left(400 \mathrm{MHz}, \mathrm{CD}_{2} \mathrm{Cl}_{2}, 25^{\circ} \mathrm{C}\right)$ : $\delta=1.05(9 \mathrm{H}, \mathrm{s}), 2.14(6 \mathrm{H}, \mathrm{s}), 2.17(6 \mathrm{H}, \mathrm{s}), 3.91(4 \mathrm{H}, \mathrm{s}), 5.79$ $(1 \mathrm{H}, \mathrm{s},-\mathrm{OH}), 6.60(2 \mathrm{H}, \mathrm{s},-\mathrm{OH}), 6.69(2 \mathrm{H}, \mathrm{s}, \mathrm{Ar}-\mathrm{H}), 6.91$ $(4 \mathrm{H}, \mathrm{s}, \mathrm{Ar}-\mathrm{H}) ;{ }^{13} \mathrm{C} \mathrm{NMR}\left(400 \mathrm{MHz}, \mathrm{CD}_{2} \mathrm{Cl}_{2}, 25^{\circ} \mathrm{C}\right): \delta=$ $16.47,20.34,31.27,34.08,37.17,117.18,124.04,124.20$, $127.55,129.60,133.75,134.12,143.46,150.09,153.56$; elemental analysis calcd. for $\mathrm{C}_{28} \mathrm{H}_{34} \mathrm{O}_{3} \mathrm{~S}_{2}$ : C 69.67, $\mathrm{H} \mathrm{7.10,} \mathrm{S}$ 13.29; found: C $69.55, \mathrm{H} 7.09, \mathrm{~S} 13.18$; MS: $\mathrm{m} / z=505.0$ $\left(\mathrm{M}+\mathrm{Na}^{+}\right)$.

\section{Synthesis of the Iron(III) Complex 4 (Scheme 2)}

The complex 4 was synthesized using the same procedure previously reported for complex $\mathbf{1}^{[11]}$ Pro-ligand $\mathbf{L} 4(0.54 \mathrm{~g}$; $0.96 \mathrm{mmol})$ was dissolved in THF $(30 \mathrm{~mL})$. The solution was added to a suspension of sodium hydride $(0.082 \mathrm{~g}$; $3.4 \mathrm{mmol})$ in THF $(20 \mathrm{~mL})$ and the mixture stirred at room temperature overnight. The resulting suspension was filtered through celite and slowly added at room temperature to $0.148 \mathrm{~g}$ of anhydrous iron(III) chloride $(0.91 \mathrm{mmol})$ dissolved in $15 \mathrm{~mL}$ of THF. The rapid change of the color to blue was observed and the reaction kept overnight at room temperature. The mixture was then filtered through a celite path and the solvent removed under reduced pressure affording a deep purple crystalline solid; yield: $0.44 \mathrm{~g} \mathrm{(78 \% );}$ elemental analysis calcd. for $\mathrm{C}_{48} \mathrm{H}_{38} \mathrm{Fe}_{2} \mathrm{Cl}_{8} \mathrm{O}_{6} \mathrm{~S}_{4}$ : C $46.70, \mathrm{H}$ 3.10, S 10.39; found: C 46.61, H 3.03, S 10.35; MS: $\mathrm{m} / z=$
$981.2\left(\mathrm{M}+\mathrm{Na}^{+}\right) ; 1354.8\left[\mathrm{M}\left(\mathrm{CH}_{3} \mathrm{CN}\right)_{2} \mathrm{~K}^{+}\right] ; \mathrm{UV}-\mathrm{Vis}: \varepsilon_{585}=$ $5441 \mathrm{~L} \cdot \mathrm{mol}^{-1} \cdot \mathrm{cm}^{-1}$.

\section{Synthesis of the Iron(III) Complex 5 (Scheme 2)}

The complex $\mathbf{5}$ was synthesized using the same procedure previously reported for complex $\mathbf{1}^{[11]}$ Pro-ligand L5 (0.94 g; $2.04 \mathrm{mmol})$ was dissolved in THF $(70 \mathrm{~mL})$. The solution was added to a suspension of sodium hydride $(0.17 \mathrm{~g}$; $7.08 \mathrm{mmol})$ in THF (30 mL) and the mixture stirred at room temperature overnight. The resulting suspension was filtered through celite and slowly added at room temperature to $0.325 \mathrm{~g}$ of anhydrous iron(III) chloride $(2.0 \mathrm{mmol})$ dissolved in $30 \mathrm{~mL}$ of THF. The rapid change of the color to the blue was observed and the reaction kept overnight. The mixture was then filtered through celite and the solvent removed under reduced pressure affording a deep purple crystalline solid; yield: $0.83 \mathrm{~g}(80 \%)$; elemental analysis calcd. for $\mathrm{C}_{48} \mathrm{H}_{44} \mathrm{Fe}_{2} \mathrm{Cl}_{2} \mathrm{O}_{6} \mathrm{~S}_{4}$ : C 56.10, H 4.32, S 12.48; found: C 56.02, H 4.28, S 12.39; MS: $m / z=981.2\left(\mathrm{M}+\mathrm{Na}^{+}\right)$; UV-Vis: $\varepsilon_{596}=$ $4757 \mathrm{~L} \cdot \mathrm{mol}^{-1} \cdot \mathrm{cm}^{-1}$.

\section{Synthesis of the Iron(III) Complex 6 (Scheme 2)}

The complex 6 was synthesized using the same procedure previously reported for complex $\mathbf{1}^{[11]}$ Pro-ligand L6 (1.62 g; $3.56 \mathrm{mmol})$ was dissolved in THF $(100 \mathrm{~mL})$. The solution was added to a suspension of sodium hydride $(0.30 \mathrm{~g}$; $12.5 \mathrm{mmol})$ in THF $(70 \mathrm{~mL})$ and the mixture stirred at room temperature overnight. The resulting suspension was filtered through celite and slowly added at room temperature to $0.567 \mathrm{~g}$ of anhydrous iron(III) chloride $(3.50 \mathrm{mmol})$ dissolved in $100 \mathrm{~mL}$ of THF. The rapid change of the color to the deep purple was observed and the reaction kept overnight. The mixture was then filtered through celite and the solvent removed under reduced pressure affording a deep purple crystalline solid; yield: $1.60 \mathrm{~g}(85 \%)$; elemental analysis calcd. for $\mathrm{C}_{56} \mathrm{H}_{62} \mathrm{Fe}_{2} \mathrm{O}_{6} \mathrm{~S}_{4}: \mathrm{C}$ 62.30, $\mathrm{H}$ 5.83, S 11.98; found: C 62.20, H 5.78, S 11.89; MS: $m / z=1072.1\left(\mathrm{M}+\mathrm{H}^{+}\right)$; UV-Vis: $\varepsilon_{586}=4962 \mathrm{~L} \cdot \mathrm{mol}^{-1} \cdot \mathrm{cm}^{-1}$.

\section{Typical Procedure for $\mathrm{CO}_{2} /$ Epoxide Coupling to Cyclic Carbonates Catalyzed by 6/TBAB (Entry 15, Table $\mathrm{S} 1$ in the Supporting Information)}

A 60-mL stainless steel pressure reactor equipped with a magnetic stirring bar was charged, under $\mathrm{CO}_{2}$ atmosphere, with $7.7 \mathrm{mg}$ of catalyst $6\left(7.15 \times 10^{-6} \mathrm{~mol}\right)$ and $23.0 \mathrm{mg}$ of TBAB $\left(7.15 \times 10^{-5} \mathrm{~mol}\right)$ dissolved in $5.0 \mathrm{~mL}$ of PO $(7.15 \times$ $\left.10^{-2} \cdot \mathrm{mol}\right)$. The reaction mixture was pressurized with $\mathrm{CO}_{2}$ at $2.0 \mathrm{MPa}$ and stirred at $120^{\circ} \mathrm{C}$ for $1 \mathrm{~h}$. The reactor was cooled with ice, the $\mathrm{CO}_{2}$ released, $1.0 \mathrm{~mL}$ of mesitylene $\left(7.15 \times 10^{-3} \mathrm{~mol}\right)$ was added as an internal standard and the mixture was analyzed by ${ }^{1} \mathrm{H}$ NMR spectroscopy using $\mathrm{CDCl}_{3}$ as solvent; yield: $52.0 \%$.

\section{Crystallographic Data Collection and Structure Determination for Complex 6}

The X-ray intensity data were measured on a Bruker SMART Apex II CCD area detector diffractometer. Cell dimensions and the orientation matrix were initially determined from a least-squares refinement on reflections mea- 
sured in three sets of 20 exposures, collected in three different $\omega$ regions, and eventually refined against all data. A full sphere of reciprocal space was scanned by $0.3^{\circ} \omega$ steps. The software SMART ${ }^{[17]}$ was used for collecting frames of data, indexing reflections, and determination of lattice parameters. The collected frames were then processed for integration by the SAINT program ${ }^{[17]}$ and an empirical absorption correction was applied using SADABS. ${ }^{[18]}$ The structure was solved by direct methods (SIR 2004) ${ }^{[19]}$ and subsequent Fourier syntheses and refined by full-matrix least-squares on $\mathrm{F}^{2}$ (SHELXTL) ${ }^{[20]}$ using anisotropic thermal parameters for all non-hydrogen atoms. All hydrogen atoms were added in calculated positions, included in the final stage of refinement with isotropic thermal parameters, $U(\mathrm{H})=1.2 \quad U_{\text {eq }}(\mathrm{C})$ $\left[U(\mathrm{H})=1.5 U_{\text {eq }}(\mathrm{C}-\mathrm{Me})\right]$, and allowed to ride on their carrier carbons. Crystal data and details of the data collection for complex 6 are reported in Table S3 and Table S4 in the Supporting Information. CCDC 1477580 contains the supplementary crystallographic data for this paper. These data can be obtained free of charge from The Cambridge Crystallographic Data Centre via www.ccdc.cam.ac.uk/data_request/ cif.

\section{Computational Protocol}

All the DFT geometry optimizations were performed at the GGA level with the Gaussian 09 set of programs, ${ }^{[21]}$ using the BP86 functional of Becke and Perdew. ${ }^{[22]}$ The electronic configuration of the molecular systems was described with the split-valence plus one polarization function basis set of Ahlrichs for $\mathrm{H}, \mathrm{C}, \mathrm{N}, \mathrm{O}, \mathrm{S}$ and $\mathrm{Br}$ (SVP keyword in Gaussian). ${ }^{[23]}$ For $\mathrm{Fe}$, we used the small-core, quasi-relativistic Stuttgart-Dresden effective core potential, with the associated triple- $\zeta$ valence basis set (SDD keywords in Gaussian09). ${ }^{[24]}$ Geometry optimizations were performed without symmetry constraints, and the characterization of the located stationary points was performed by analytical frequency calculations. For better energetics, energies were re-evaluated via single point calculations on the BP86/SVP optimized geometries with the triple- $\zeta$ plus one polarization function basis set proposed by Ahlrichs (TZVP keyword in Gaussian) ${ }^{[25]}$ using the M06 functional. ${ }^{[26]}$ Solvent effects (propylene oxide) were estimated with the polarizable continuum solvation model PCM. ${ }^{[27]}$ To this M06/TZVP electronic energy in solvent, zero point energy and thermal corrections were included from the gas-phase frequency calculations at the BP86/SVP level. ${ }^{[28]}$ All the calculations were performed with an unrestricted DFT formalism, assuming the two Fe centers in a high spin state.

\section{Acknowledgements}

Financial support is acknowledged from the Ministero dell'Istruzione dell'Università e della Ricerca (MIUR, Roma, Italy for FARB 2015) and the SPRING cluster (REBIOCHEM research project CTN01 00063 49393). LC acknowledges the King Abdullah University of Science and Technology for supporting this research. The Centro di Tecnologie Integrate per la Salute (Project PONa3_00138) for the $600 \mathrm{MHz} N \mathrm{NR}$ instrumental time is acknowledged. The authors are also grateful to Dr. Guglielmo Monaco from University of Salerno for useful discussion, Dr. Patrizia Oliva and Dr. Patrizia Iannece from University of Salerno for technical assistance.

\section{References}

[1] a) J. Qiao, Y. Liu, F. Hong, J. Zhang, Chem. Soc. Rev. 2014, 43, 631-675; b) C. Maeda, Y. Miyazaki, T. Ema, Catal. Sci. Technol. 2014, 4, 1482-1497; c) M. Aresta, A. Dibenedetto, A. Angelini, Chem. Rev. 2014, 114, 1709-1742; d) I. Omae, Coord. Chem. Rev. 2012, 256, 1384-1405; e) M. Cokoja, C. Bruckmeier, B. Rieger, W. A. Herrmann, F. E. Kühn, Angew. Chem. 2011, 123, 8662-8690; Angew. Chem. Int. Ed. 2011, 50, 8510-8537; f) E. A. Quadrelli, G. Centi, J.-L. Duplan, S. Perathoner, ChemSusChem 2011, 4, 1194-1215; g) D. J. Darensbourg, Inorg. Chem. 2010, 49, 10765-10780; h) M. Aresta, A. Dibenedetto, Dalton Trans. 2007, 29752992 ; i) T. Sakakura, J.-C. Choi, H. Yasuda, Chem. Rev. 2007, 107, 2365-2387; j) Activation of Carbon Dioxide, (Ed.: S. L. Suib), Elsevier, Amsterdam, 2013.

[2] a) C. J. Whiteoak, A. W. Kleij, Synlett 2013, 24, 17481756 ; b) M. North, R. Pasquale, C. Young, Green Chem. 2010, 12, 1514-1539; c) A. Decortes, A. M. Castilla, A. W. Kleij, Angew. Chem. 2010, 122, 1001610032; Angew. Chem. Int. Ed. 2010, 49, 9822-9837; d) C. Martín, G. Fiorani, A. W. Kleij, ACS Catal. 2015, 5, 1353-1370; e) J. W. Comerford, I. D. V. Ingram, M. North, X. Wu, Green Chem. 2015, 17, 1966-1987.

[3] a) X.-B. Lu, D. J. Darensbourg, Chem. Soc. Rev. 2012, 41, 1462-1484; b) D. J. Darensbourg, S. J. Wilson, Green Chem. 2012, 14, 2665-2671; c) X.-B. Lu, W.-M. Ren, G.-P. Wu, Acc. Chem. Res. 2012, 45, 1721-1735; d) S. Klaus, M. W. Lehenmeier, C. E. Anderson, B. Rieger, Coord. Chem. Rev. 2011, 255, 1460-1479; e) M. R. Kember, A. Buchard, C. K. Williams, Chem. Commun. 2011, 47, 141-163; f) D. J. Darensbourg, Chem. Rev. 2007, 107, 2388-2410; g) G. W. Coates, D. R. Moore, Angew. Chem. 2004, 116, 6784-6806; Angew. Chem. Int. Ed. 2004, 43, 6618-6639.

[4] a) Element Recovery and Sustainability, RSC Green Chemistry series, Vol. 22, (Ed.: A. J. Hunt), RSC Publishing, Cambridge, 2013; b) R. M. Izatt, S. R. Izatt, R. L. Bruening, N. E. Izatt, B. A. Moyer, Chem. Soc. Rev. 2014, 43, 2451-2475.

[5] a) X.-F. Liu, Q.-W. Song, S. Zhang, L.-N. He, Catal. Today 2016, 263, 69-74; b) M. Cokoja, M. E. Wilhelm, M. H. Anthofer, W. A. Herrmann, F. E. Kühn, ChemSusChem 2015, 8, 2436-2454; c) G. Fiorani, W. Guo, A. W. Kleij, Green Chem. 2015, 17, 1375-1389; d) Q. He, J. W. O'Brien, K. A. Kitselman, L. E. Tompkins, G. C. T. Curtis, F. M. Kerton, Catal. Sci. Technol. 2014, 4, 1513-1528; e) H. Li, P. S. Bhadury, B. Song, S. Yang, RSC Adv. 2012, 2, 12525-12551; f) Z.-Z. Yang, Y.-N. Zhao, L.-N. He, RSC Adv. 2011, 1, 545-567.

[6] a) X.-B. Lu, Y.-J. Zhang, K. Jin, L.-M. Luo, H. Wang, J. Catal. 2004, 227, 537-541; b) D. Tian, B. Liu, Q. Gan, H. Li, D. J. Darensbourg, ACS Catal. 2012, 2, 20292035; c) J. A. Castro-Osma, C. Alonso-Moreno, A. Lara-Sanchez, J. Martinez, M. North, A. Otero, Catal. Sci. Technol. 2014, 4, 1674-1684; d) J. Martínez, J. A. 
Castro-Osma, A. Earlam, C. Alonso-Moreno, A. Otero, A. Lara-Sánchez, M. North, A. Rodríguez-Diéguez, Chem. Eur. J. 2015, 21, 9850-9862; e) M. North, S. C. Z. Quek, N. E. Pridmore, A. C. Whitwood, X. Wu, ACS Catal. 2015, 5, 3398-3402; f) J. A. Castro-Osma, M. North, X. Wu, Chem. Eur. J. 2016, 22, 2100-2107; g) S. H. Kim, D. Ahn, M. J. Go, M. H. Park, M. Kim, J. Lee, Y. Kim, Organometallics 2014, 33, 2770-2775; h) M. Cozzolino, K. Press, M. Mazzeo, M. Lamberti, ChemCatChem 2016, 8, 455-460; i) S. Supasitmongkol, P. Styring, Catal. Sci. Technol. 2014, 4, 1622-1630; j) Y. Ren, O. Jiang, H. Zeng, Q. Mao, H. Jiang, RSC Adv. 2016, 6, 3243-3249; k) M. A. Fuchs, C. Altesleben, T. A. Zevaco, E. Dinjus, Eur. J. Inorg. Chem. 2013, 2013, 4541-4545.

[7] a) J. Melendez, M. North, P. Villuendas, Chem. Commun. 2009, 2577-2579; b) W. Clegg, R. W. Harrington, M. North, R. Pasquale, Chem. Eur. J. 2010, 16, 6828-6843; c) M. North, C. Young, Catal. Sci. Technol. 2011, 1, 93-99; d) C. Beattie, M. North, P. Villuendas, C. Young, J. Org. Chem. 2013, 78, 419-426; e) J. A. Castro-Osma, A. Lara-Sanchez, M. North, A. Otero, P. Villuendas, Catal. Sci. Technol. 2012, 2, 1021-1026; f) J. A. Castro-Osma, M. North, X. Wu, Chem. Eur. J. 2014, 20, 15005-15008; g) M. North, B. Wang, C. Young, Energy Environ. Sci. 2011, 4, 4163-4170; h) J. Melendez, M. North, P. Villuendas, C. Young, Dalton Trans. 2011, 40, 3885-3902; i) W. Clegg, R. W. Harrington, M. North, P. Villuendas, J. Org. Chem. 2010, 75 , 6201-6207; j) M. North, P. Villuendas, C. Young, Chem. Eur. J. 2009, 15, 11454-11457; k) M. North, R. Pasquale, Angew. Chem. 2009, 121, 2990-2992; Angew. Chem. Int. Ed. 2009, 48, 2946-2948; 1) J. Meléndez, M. North, R. Pasquale, Eur. J. Inorg. Chem. 2007, 2007, 3323-3326.

[8] a) C. J. Whiteoak, N. Kielland, V. Laserna, E. C. Escudero-Adán, E. Martin, A. W. Kleij, J. Am. Chem. Soc. 2013, 135, 1228-1231; b) C. J. Whiteoak, N. Kielland, V. Laserna, F. Castro-Gómez, E. Martin, E. C. EscuderoAdán, C. Bo, A. W. Kleij, Chem. Eur. J. 2014, 20, 2264 2275 ; c) J. Rintjema, W. Guo, E. Martin, E. C. Escudero-Adán, A. W. Kleij, Chem. Eur. J. 2015, 21, 10754 10762.

[9] a) I. Bauer, H.-J. Knölker, Chem. Rev. 2015, 115, 3170 3387; b) C.-L. Sun, B.-J. Li, Z.-J. Shi, Chem. Rev. 2010 , 111, 1293-1314; c) A. Correa, O. Garcia Mancheno, C. Bolm, Chem. Soc. Rev. 2008, 37, 1108-1117; d) C. Bolm, J. Legros, J. Le Paih, L. Zani, Chem. Rev. 2004, 104, 6217-6254.

[10] a) M. Taherimehr, J. P. C. C. Sertã, A. W. Kleij, C. J. Whiteoak, P. P. Pescarmona, ChemSusChem 2015, 8, 1034-1042; b) X. Sheng, L. Qiao, Y. Qin, X. Wang, F. Wang, Polyhedron 2014, 74, 129-133; c) M. Adolph, T. A. Zevaco, C. Altesleben, O. Walter, E. Dinjus, Dalton Trans. 2014, 43, 3285-3296; d) M. A. Fuchs, T. A. Zevaco, E. Ember, O. Walter, I. Held, E. Dinjus, M. Doring, Dalton Trans. 2013, 42, 5322-5329; e) M. Taherimehr, S. M. Al-Amsyar, C. J. Whiteoak, A. W. Kleij, P. P. Pescarmona, Green Chem. 2013, 15, 3083 3090; f) C. J. Whiteoak, E. Martin, E. Escudero-Adán, A. W. Kleij, Adv. Synth. Catal. 2013, 355, 2233-2239; g) C. J. Whiteoak, E. Martin, M. M. Belmonte, J.
Benet-Buchholz, A. W. Kleij, Adv. Synth. Catal. 2012, 354, 469-476; h) C. J. Whiteoak, B. Gjoka, E. Martin, M. M. Belmonte, E. C. Escudero-Adán, C. Zonta, G. Licini, A. W. Kleij, Inorg. Chem. 2012, 51, 1063910649 ; i) J. E. Dengler, M. W. Lehenmeier, S. Klaus, C. E. Anderson, E. Herdtweck, B. Rieger, Eur. J. Inorg. Chem. 2011, 2011, 336-343; j) A. Buchard, M. R. Kember, K. G. Sandeman, C. K. Williams, Chem. Commun. 2011, 47, 212-214; k) D. Alhashmialameer, J. Collins, K. Hattenhauera, F. M. Kerton, Catal. Sci. Technol. 2016, DOI: 10.1039/C6CY00477F.

[11] a) A. Buonerba, F. Della Monica, A. De Nisi, E. Luciano, S. Milione, A. Grassi, C. Capacchione, B. Rieger, Faraday Discuss. 2015, 183, 83-95; b) A. Buonerba, A. De Nisi, A. Grassi, S. Milione, C. Capacchione, S. Vagin, B. Rieger, Catal. Sci. Technol. 2015, 5, 118-123.

[12] a) D. F. Evans, J. Chem. Soc. 1959, 2003-2005; b) J. L. Deutsch, S. M. Poling, J. Chem. Educ. 1969, 46, 167; c) Physical Methods in Bioinorganic Chemistry, (Ed.: L. Que Jr), University Science Books, Sausalito, CA, 2000.

[13] Advanced Inorganic Chemistry, (Ed.: F. A. Cotton, G. Wilkinson, C. A. Murillo, E. M. Bochmann), Wiley, 2009.

[14] a) B. L. Morris, A. Wold, Rev. Sci. Instrum. 1968, 39 , 1937-1941; b) L. F. Lindoy, V. Katovic, D. H. Busch, J. Chem. Educ. 1972, 49, 117.

[15] R. Metzinger, C. Z. Limber, Z. Anorg. Allg. Chem. 2012, 638, 2225-2234.

[16] a) V. D'Elia, A. A. Ghani, A. Monassier, J. SofackKreutzer, J. D. A. Pelletier, M. Drees, S. V. C. Vummaleti, A. Poater, L. Cavallo, M. Cokoja, J.-M. Basset, F. E. Kühn, Chem. Eur. J. 2014, 20, 11870-11882; b) V. D'Elia, H. Dong, A. J. Rossini, C. M. Widdifield, S. V. C. Vummaleti, Y. Minenkov, A. Poater, E. AbouHamad, J. D. A. Pelletier, L. Cavallo, L. Emsley, J.-M. Basset, J. Am. Chem. Soc. 2015, 137, 7728-7739.

[17] SMART \& SAINT Software Reference Manuals, version 5.051, Windows NT Version, Bruker Analytical Xray Instruments Inc.: Madison, WI, 1998.

[18] G. M. Sheldrick, $S A D A B S$, program for empirical absorption correction, University of Göttingen, Germany, 1996.

[19] M. C. Burla, R. Caliandro, M. Camalli, B. Carrozzini, G. L. Cascarano, L. De Caro, C. Giacovazzo, G. Polidori, R. Spagna, J. Appl. Crystallogr. 2005, 38, 381-388.

[20] G. M. Sheldrick, SHELXTLplus Windows NT Version, Structure Determination Package, Version 5.1. Bruker Analytical X-ray Instruments Inc.: Madison, WI, USA, 1998.

[21] M. J. Frisch, et al., Gaussian 09, Revision A.1, Gaussian, Inc., Wallingford, CT, 2009.

[22] a) A. D. Becke, Phys. Rev. A 1988, 38, 3098-3100; b) J. P. Perdew, Phys. Rev. $B$ 1986, 33, 8822-8824; c) J. P. Perdew, Phys. Rev. B 1986, 34, 7406-7406.

[23] A. Schäfer, H. Horn, R. Ahlrichs, J. Chem. Phys. 1992, 97, 2571-2577.

[24] a) U. Haeusermann, M. Dolg, H. Stoll, H. Preuss, Mol. Phys. 1993, 78, 1211-1224; b) W. Kuechle, M. Dolg, H. Stoll, H. Preuss, J. Chem. Phys. 1994, 100, 7535-7542; c) T. Leininger, A. Nicklass, H. Stoll, M. Dolg, P. Schwerdtfeger, J. Chem. Phys. 1996, 105, 1052-1059. 
[25] Y. Zhao, D. G. Truhlar, Theor. Chem. Acc. 2008, 120, 215-241.

[26] A. Schaefer, C. Huber, R. Ahlrichs, J. Chem. Phys. 1994, 100, 5829-5835.

[27] a) V. Barone, M. Cossi, J. Phys. Chem. A 1998, 102, 1995-2001; b) J. Tomasi, M. Persico, Chem. Rev. 1994, 94, 2027-2094.
[28] a) A. Poater, E. Pump, S. V. C. Vummaleti, L. Cavallo, J. Chem. Theory Comput. 2014, 10, 4442-4448; b) E. Pump, C. Slugovc, L. Cavallo, A. Poater, Organometallics 2015, 34, 3107-3111; c) S. Manzini, A. Poater, D. J. Nelson, L. Cavallo, S. P. Nolan, Chem. Sci. 2014, 5, 180-188. 